\title{
Representação social de mães sobre alimentação e uso de estimulantes do apetite em crianças: satisfação, normalidade e poder
}

\section{| ${ }^{1}$ Diego Carneiro Ramos, ${ }^{2}$ Thereza Christina Bahia Coelho |}

Resumo: Este estudo teve como objetivo identificar as representações sociais elaboradas por mães sobre o apetite dos filhos e os medicamentos utilizados para modificá-lo. A abordagem qualitativa desta pesquisa empregou como suporte a teoria das representações sociais. Por meio de entrevistas realizadas com 15 mães que administraram em seus filhos medicamentos para estimular o apetite, foi possível identificar uma insatisfação materna com o volume habitual e seletividade de alimentos ingeridos por seus filhos. Essas foram as principais razões para o uso de medicamentos. Outras razões que encontram espaço são o desenvolvimento da criança, com ganho de massa corpórea, além da vontade de regular as horas em que a criança deveria comer. Esses resultados apontam para a importância das representações sociais maternas sobre a percepção corporal, papel dos alimentos e medicamentos nas práticas do cuidado alimentar infantil.

> Palavras-chave: alimentação infantil; representações sociais; estimulantes do apetite.
1 Universidade Estadual de Feira de Santana. Feira de SantanaBA, Brasil (diegocarneiroramos@ gmail.com).

2 Universidade Estadual de Feira de Santana. Feira de SantanaBA, Brasil (tcuide@yahoo. com.br).
Recebido em: 28/12/2015 Aprovado em: 25/09/2016 


\section{Introdução}

Apesar de a alimentação ser uma necessidade fisiológica de todos os indivíduos, ela não se restringe apenas a essa função. A alimentação se insere em um universo simbólico que vai muito além dos aspectos nutricionais e que se inicia desde cedo, levando os signos até a vida adulta (STEFANELLO, 2008). Por essa razão, investigaçóes que tragam uma observação aprofundada, compreensiva e interpretativa sobre os sentidos e significados atribuídos pelos sujeitos aos alimentos, ao ato de comer e se alimentar são importantes, especialmente quando envolvem o cuidado alimentar na infância. A exploração dos valores sociais e culturais relacionados a essa prática pode contribuir para o subsídio de ações e políticas de educação em saúde (SOARES; COELHO, 2008; SOARES, 2011).

Diversos estudos têm ressaltado o papel da valorização sociofamiliar do ganho de peso da criança como um indicativo de saúde. A ideia de que a criança "gordinha" apresenta boa saúde e é mais bem cuidada pelos pais acaba por prejudicar a percepção de mães com relação ao sobrepeso de seus filhos. As interpretações das mães acerca da relação alimento-peso-saúde podem originar uma busca por medicamentos que tenham a capacidade, em sua crença, de intervir no apetite ou no peso das crianças (BOA-SORTE et al., 2007; SOARES, 2011; MARTÍN; CASTILLO, 2000).

É rotina nos consultórios de pediatria o motivo da consulta pediátrica ser determinado pela queixa materna de inapetência dos filhos, em particular aquela que envolve seletividade alimentar. Nesses casos, é comum a solicitação pelos pais da prescrição de medicamentos ou orientações dietéticas curativas (KACHANI et al., 2005; POCKELS et al, 1994).

A crença de que as crianças são incapazes de regular sua ingestão alimentar e a recusa alimentar deixam os pais angustiados, gerando conflitos manifestados por sentimentos de culpa, incompetência e frustração. Disso decorre o emprego de estratégias coercitivas e controladoras na alimentação das crianças (KACHANI et al., 2005; CERRO et al., 2002).

As mães anseiam pela administração de alimentos conforme o seu julgamento do que é ideal a criança comer. Para Salve e Silva (2009), as mulheres realizam sua interpretação sob a baliza do seu senso comum e, a partir disso, definem o que é ou não adequado para o filho. Dessa forma, sentem-se seguras para continuar seguindo suas próprias percepções em relação à alimentação da criança. 
Pesquisar sobre a alimentação das crianças e o significado dos medicamentos no processo de recuperação do apetite significa, então, interrogar sobre os valores que orientam a alimentação e a saúde das pessoas. É considerar que as mães, figuras determinantes na educação alimentar e no trato à saúde infantil, trazem consigo experiências, vivências e crenças que influenciam de maneira significativa essas atitudes, que serão internalizadas pela criança na forma de hábitos e gostos alimentares levados para a vida adulta (SIMON; SOUZA; SOUZA, 2003; CHUPROSKI; MELLO, 2009).

As práticas alimentares são, portanto, socialmente estruturadas, carregadas de valores simbólicos e densamente envolvidas em aspectos culturais, de gênero, relacionais, acabando por refletir as representações sociais não apenas do contexto onde se apresentam, mas também da posição social ocupada. É, portanto, importante determinante na construção da identidade, da imagem de si e do outro (STEFANELLO, 2008).

A biopolítica vem utilizando-se cada vez de mecanismos mais sutis e economicamente mais racionais para controlar indivíduos e populações. Aos mecanismos de poder sobre o corpo dos indivíduos, como vigilância e treinamento, Foucault (2005) denomina poder disciplinar. Aos fenômenos populacionais, de massa, biológicos, sociobiológicos, ele chama de mecanismos regulamentadores, onde se incluem os cuidados dispensados às crianças. Entre o poder disciplinar e o regulamentador, o que circula é a norma.

Foucault fala em poder disciplinar para explicar uma forma de poder que atua sobre os corpos usando a vigilância e a punição como maneiras de adestrar e docilizar o indivíduo, construindo um sujeito com utilidade. A disciplina, para Foucault, é uma técnica de distribuição dos indivíduos através da inserção dos corpos em um espaço individualizado, classificatório, formado a partir de mecanismos que irão tornar o sujeito tanto mais obediente quanto mais útil. Já o poder regulamentador ou biopoder atua por meio de uma diversidade de processos sutis que buscam normalizar a população infantil, que deve ter certo peso, certa altura, aparência, enfim, um determinado corpo a ser moldado por práticas e hábitos alimentares.

As preferências e aversões alimentares também são moduladas pelos afetos presentes nas relações das crianças com suas mães. Afinal, "el gusto o la aversión 
hacia a um alimento puede darse em funcion de dónde se coma, cómo se coma, cuándo se coma o con quién se coma" (APARICI, 2007, p. 157).

A formação do gosto e da aversão alimentar sofre ainda restrições externas de natureza econômica. Na Inglaterra, por exemplo, as mulheres de baixa escolaridade sentiam fortemente o peso de não ter controle sobre sua alimentação e a de seus filhos (BARKER et al, 2008; EXPERTISE COLLECTIVE, 2014). Desse modo, o baixo controle sobre a oferta alimentar pode estar operando um deslocamento na direção do apetite infantil, tendo como instrumento viabilizador a medicação. Nesse sentido, Castro (2000) alerta que fatores diversos contribuem nas práticas inadequadas de utilização de medicamentos por indivíduos, incluindo até sincretismos culturais.

Nesse cenário, insere-se o medicamento, instrumento de transformação da saúde e produto repleto de carga simbólica. A eficácia do processo de significação do medicamento apresenta íntima relação com as crenças e valores vivenciados no imaginário coletivo (NASCIMENTO, 2005). Para Aquino (2008, p. 735) o resultado acaba por ser "uma crença excessiva e ingênua no poder dos medicamentos".

Diante da escassez de estudos que focalizam as estratégias medicamentosas enquanto elemento do processo educativo e disciplinador na prática alimentar, coube a este estudo interrogar as razões que orientam a decisão das mães de administrar estimulantes de apetite às suas crianças e as crenças que dão suporte a essa decisão. $\mathrm{Ou}$, de quais sentidos esse ato se reveste para essas mães.

Seguindo tais questionamentos, este trabalho tem como objetivo identificar as representações sociais elaboradas pelas mães sobre o apetite dos filhos e sobre os medicamentos administrados para modificá-lo.

\section{Métodos}

A abordagem qualitativa foi considerada mais adequada para responder às questôes direcionadas ao objeto de estudo, pois possibilita a percepção e descrição minuciosa da realidade dos sujeitos, atingindo uma compreensão da situação de vida em maior profundidade. Para isso, a Teoria das Representações Sociais foi utilizada como suporte, possibilitando melhor apreensão da relação entre, de um lado, conhecimentos, crenças e valores das mães (acerca da alimentação dos 
filhos e medicamentos) e, de outro, a tomada da decisão de usar medicamentos para alterar o perfil alimentar da criança.

Moscovici (2005) afirma que a finalidade de todas as representações é tornar familiar algo não familiar. $\mathrm{O}$ autor considera que os universos consensuais são espaços onde os indivíduos desejam ficar, pois não há conflito e tudo o que é dito ou feito apenas confirma as crenças e as interpretações adquiridas. Por outro lado, objetos, pessoas e acontecimentos não familiares são alvos de um processo de interiorização nesse universo consensual, afinal o não familiar perturba e causa tensão.

Um bairro da área urbana de um pequeno município do estado da Bahia foi o local escolhido como campo do estudo. Foram entrevistados 15 sujeitos residentes dessa área, quantidade obtida após se observar a saturação dos dados e o alcance de um volume satisfatório de informações, seguindo recomendaçôes de Minayo (1998).

Os sujeitos da pesquisa eram mães que tinham recentemente administrado (180 dias) medicamentos estimulantes de apetite para crianças menores de cinco anos. A seleção foi intencional, guiada pelos agentes comunitários da área trabalhada, que conheciam quais mães atendiam a esse critério. As mães foram informadas do objetivo e dos procedimentos da pesquisa; as que concordaram (mediante assinatura do Termo de Consentimento Livre e Esclarecido) fizeram parte da pesquisa.

A pesquisa foi conduzida dentro dos padrões exigidos pela Resolução no 466/13 do Conselho Nacional de Saúde e aprovada pelo Comitê de Ética em Pesquisa da Universidade Estadual de Feira de Santana, sob o parecer no 411.609. $\mathrm{Na}$ intenção de garantir o sigilo, os fragmentos de depoimentos transcritos foram identificados pela abreviação "Ent." (Entrevistado) seguida de um número.

A coleta de dados foi realizada utilizando-se da técnica de entrevista semiestruturada, com auxílio de um roteiro de entrevista. Dados socioeconômicos também foram coletados, a fim de caracterizar a população pesquisada.

Os textos gerados pela entrevista semiestruturada e pelas impressões do pesquisador foram analisados com base na técnica de Análise de Conteúdo. Essa técnica busca sua lógica na interpretação cifrada do material de caráter qualitativo.

Seguindo as recomendações de Jodelet (2001), as representações sociais foram analisadas articulando elementos afetivos, mentais e sociais, integrando a cognição, 
a linguagem e a comunicação às relações sociais que afetam essas representações. A representação que relaciona o sujeito com o objeto deve ser devidamente identificada em comportamentos e comunicações que de fato ocorram.

\section{Resultados e discussão}

A alimentação de crianças pequenas é uma das funções primordiais do cuidado materno. Nas comunidades rurais ou nas urbanas de periferia, muitas famílias ainda permanecem estruturadas de forma tradicional, não sendo incomum a formação de subcomunidades familiares onde parentes residem próximos uns dos outros formando uma rede de apoio e relações sociais fortes que compartilham representações, valores e modos de gerenciar a vida. Para compreender as práticas de administração de estimulantes do apetite, é necessário conhecer um pouco do perfil social do grupo estudado.

As mães, sujeitos da pesquisa, eram relativamente jovens, tendo idade média de 26,9 anos. O número total de filhos das entrevistadas somou 26 crianças, alcançando uma média de 1,7 por mulher. A idade média de todos os filhos foi 4,2 anos. O número médio de pessoas convivendo juntas era de 4,3 indivíduos. Seis das 15 mães entrevistadas não conviviam com um companheiro.

As famílias tinham renda familiar muito baixa, sendo que 33,3\% ganhavam menos que um salário mínimo, 33,3\% ganhavam um salário mínimo, 20\% ganhavam entre um e dois salários-mínimos, 6,7\% ganhavam entre dois e três salários mínimos e outros $6,7 \%$ ganhavam entre quatro e cinco salários mínimos. Essa renda familiar estava muito ligada à ocupação profissional das mães. Apenas três tinham trabalho fixo.

A escolaridade das mães mostrava pouco tempo de estudo. Menos da metade das entrevistadas tinha completado o ensino médio (40\%). Não tinham terminado o ensino fundamental $26,6 \%$ das mães. O enquadramento de suas características socioeconômicas forma a Tabela 1 . 
Tabela 1. Perfil socioeconômico das mães pesquisadas

\begin{tabular}{|c|c|c|}
\hline Características & $\mathbf{N}$ & $\%$ \\
\hline \multicolumn{3}{|c|}{ IDADE } \\
\hline 18 a 24 anos & 4 & 26,7 \\
\hline 24 a 30 anos & 8 & 53,3 \\
\hline 30 a 36 anos & 1 & 6,7 \\
\hline 36 a 41 anos & 2 & 13,3 \\
\hline Total & 15 & 100,0 \\
\hline \multicolumn{3}{|c|}{ ESCOLARIDADE } \\
\hline Analfabeta & 0 & 0 \\
\hline Fundamental incompleto & 4 & 26,7 \\
\hline Fundamental completo & 2 & 13,3 \\
\hline Ensino médio incompleto & 3 & 20,0 \\
\hline Ensino médio completo & 6 & 40,0 \\
\hline Superior incompleto/completo & 0 & 0 \\
\hline Total & 15 & 100,0 \\
\hline \multicolumn{3}{|c|}{ RENDA FAMILIAR } \\
\hline < 1 salário mínimo & 5 & 33,3 \\
\hline 1 salário mínimo & 5 & 33,3 \\
\hline Entre 1 a 2 salários-mínimos & 3 & 20,0 \\
\hline Entre 2 a3 salários-mínimos & 1 & 6,7 \\
\hline Entre 3 a 4 salários-mínimos & 0 & 0 \\
\hline Entre 4 a 5 salários-mínimos & 1 & 6,7 \\
\hline Total & 15 & 100,0 \\
\hline
\end{tabular}

\section{A mãe como cuidadora}

A participação das mães no cuidado da alimentação das crianças pequenas é enxergada por Romanelli (2006) como carregada de valores simbólicos. Para o autor, o caráter social da alimentação está presente desde o nascimento, pois o leite materno propicia o contato do filho com o corpo da mãe, mediado pelo 
seio. A alimentação no início da vida humana torna-se, assim, associada a afeto e proteção, sendo o seu preparo ligado de forma permanente ao universo feminino. Esse vínculo estreito prossegue durante a existência humana, alicerçada na divisão sexual do trabalho. Fica, portanto, centrado na figura materna o aprendizado dos hábitos alimentares da criança.

Desse modo, persiste aqui, como incumbência materna, a produção de refeições, a preocupação com a falta de apetite e as escolhas referentes a essa parcela do cuidado. Essa carga de responsabilidades enquanto exigência social deixava as mães inquietas quando os filhos não atendiam às expectativas de alimentação esperada. Quando o filho não come, rejeita os alimentos, está desqualificando a competência materna de garantir a sua alimentação.

Neste estudo, foi esse conjunto de situações que inclinavam as mães a tomar um posicionamento: ou a busca de recomendações médicas ou a compra, por automedicação, de produtos farmacêuticos para modificar o exercício alimentar dos seus filhos.

\section{O significado do comer e o problema da recusa}

É preciso advertir que a prática de alimentar as crianças não se restringe apenas ao administrar o alimento e garantir a refeição. É somado a isso o processo educativo, no qual a mãe transporta ao filho valores da própria família. Mesmo sendo o ato de comer algo natural e biológico, as práticas alimentares situamse no campo dos sistemas simbólicos. A comida é uma categoria na qual as sociedades constroem representaçōes sobre si próprias, definindo sua identidade em relação a outras sociedades, das quais se diferenciam, também, por seus hábitos alimentares (ROMANELLI, 2006).

Essa carga simbólica que envolve o alimento traz grandes expectativas afetivas para a mãe. No momento da alimentação, as mães anseiam por períodos sem conflitos, períodos de amor e despreocupação (PELEGRIN, 2008). E quando essas expectativas não se realizam, a frustração acontece.

Nas mães - desta pesquisa no município baiano - essas frustrações acontecem porque suas crianças apresentam rejeição aos alimentos, indisciplina com relação aos horários estabelecidos pelas mães às refeições, seleção do que vão querer comer e, por vezes, perda de peso. 
Era comum que as mães prezassem que sua criança comesse bastante. Era importante que o filho comesse mais. Que não rejeitasse a comida, que aceitasse as comidas que a mãe disponibilizava para ele.

Comer bem é quando a criança gosta de tudo, que não reclama do que você dá, que ele se sente bem com o que come. (Ent. 10)

Eles eram ruim de comer, colocava a comida e eles não comiam [...]. Dá na boca dele, depois ele enjoa [...]. Eu queria que ele comesse mais. (Ent.6)

Eu gosto de menino que fica comendo sabe? E ele não é assim. Pra comer eu tenho que ta pegando ele, colocando no colo, levando pra frente da televisão [tom de voz de quem está explicando uma rotina] pegando ele pra que ele coma uma fruta, para que ele coma meio-dia bem, para que ele tome o suco todo, entendeu? (Ent. 5)

O não alcance desse objetivo foi o principal motivo do uso dos medicamentos estimulantes de apetite neste trabalho.

A mesma preocupação sobre a quantidade dos alimentos foi encontrada no trabalho etnográfico de Pelegrin (2008). A autora constatou que as mães pareciam valorizar a boa alimentação mais pelo volume que a criança é capaz de ingerir do que pela densidade energética que a alimentação proporcionava. As mães acreditam que comer muito é comer bem. O fato é que, quando a preocupação centra-se apenas na quantidade de comida, perde-se a oportunidade de que se desenvolvam hábitos e atitudes relacionados a padrões de alimentos mais adequados do ponto de vista qualitativo (RAMOS; STEIN, 2002). Isso pode gerar um problema futuro, pois a aquisição de hábitos alimentares inadequados pela criança é responsável por diversos problemas de saúde, como obesidade, desnutrição e anemia (PELEGRIN, 2008).

A criança que não comia a quantidade esperada era, frequentemente, nesse estudo, descrita como "enjoada". A recusa, portanto, era mal tolerada.

As mães ansiavam que o filho despertasse para o ato de comer, que em suas leituras apresentava-se reprimido. Esse apetite reprimido era explicado como consequência de alterações fisiológicas, como doenças, infecções parasitárias ou de modificaçôes do crescimento, como o nascimento dos dentes.

Eu acho que, assim, a falta de apetite pode ser verme né? Alguma gripe que teve forte. (Ent. 14)

Assim, eu acho que começou a perda de peso com o nascimento dos dentes deles, eles ficaram um pouco gripados, com febre e aí perderam o apetite. (Ent. 1) 
$\mathrm{O}$ apetite provocado pelo medicamento traria senso de iniciativa para a criança. Esta buscaria o alimento, não dependendo da mãe para essa tarefa e auxiliando, inclusive, na diminuição dos desgastes físico e emocional da mãe decorrentes dessa atividade:

[...] E quando eu estou dando o remédio, ele fica pedindo comida! O que eu faço: deixo as frutas fácil, pra que ele tenha a vontade, deixo a feira de bolacha fácil também no armário. E aí quando eu não estou dando o remédio, ele nem vai lá. E quando eu to dando ele vai! É bolacha, é fruta. "Mamãe eu quero suco" ele nem fica esperando eu oferecer. (Ent.5)

Quando o medicamento estimulante do apetite conseguia fazer com que a criança comesse em frequência e volumes maiores, era difícil disfarçar, na entrevista, a intensa satisfação:

A fome dele era muita (riso discreto), toda hora ele tava comendo. Comia na hora certa e toda hora tava merendando. (Ent.8)

Ele comia um pouco, mas depois que a gente começou a dar, ele comia mais, toda hora comia, lanchava, assim que era difícil ele comer merenda, ele já comia. (Ent.2)

Observou-se até aqui o incômodo generalizado que a falta de apetite provoca na mãe. O comportamento infantil era tido como fora da normalidade, pois criança "normal" come muito e na hora certa. Se isso não acontece, algo está errado, e a mãe busca interpretar esse acontecimento e intervir de acordo com essa interpretação, que é sempre socialmente dada, construída dentro do meio social em que vive, pois como lembra Canguilhem (2009), o corpo humano é, em certo sentido, produto da atividade social.

$\mathrm{Na}$ interpretação das mães, a condição normal estaria superada pela patologia ou anormalidade. Mas é preciso pensar no que Canguilhem diz a respeito da normalidade, quando sugere que num determinado meio um ser vivo é normal na medida em que ele é a solução funcional encontrada pela vida para responder as exigências do meio (CANGUILHEM, 2009). Sendo assim, as constantes fisiológicas expressariam o efeito das condiçôes externas de existência sobre o ser vivo e nosso entendimento acerca do valor normativo das constantes seria desprovido de sentido.

Mesmo assim, a definição de falta de apetite que cada mãe tem revela as representações sociais envolvidas no ato da fome e da alimentação. Em certos casos, essa razão pode estar tão bem estabelecida, tão enraizada, que pode ser entendida como "genética", sendo impraticável fugir dela. 
Sabe que eu não sei explicar. Eu acho assim, sei lá, que vem de família, talvez a pessoa

já é. Vamos supor que eu sou uma pessoa ruim de apetite e talvez meu filho tenha a mesma geração. Talvez seja assim, eu imagino que seja isso. (Ent.10)

Essa carga trazida nos genes, fruto de herança familiar, também foi encontrada em outro estudo como um argumento de mães para explicar o excesso de peso de seus filhos (JAIN et al., 2001). O trabalho qualitativo com grupo focal descreve uma crença dominante das mães de que o tamanho de uma criança e o padrão de crescimento seria fixado ou predestinado, um metabolismo herdado, naturalmente programado.

Quando buscavam definir a falta de apetite, as respostas das mães abrangiam a recusa da comida e a consequente perda de peso. A perda de peso gera intensa aflição das mães, pois pode significar para os outros a prova do descuido com a criança, da falta do zelo materno (SOARES; COELHO, 2008). Falta de apetite, portanto é:

[...] ele não se alimentar direito. É perder peso, como ele tava perdendo. Come a comida, mas não come toda, larga. Uma merenda que der não merenda certo. (Ent. 11)

Em outros momentos, as crianças são descritas como resistentes ao ato de comer ou muito seletivas, apresentando um comportamento "birrento", escolhendo o que querem comer ou não, gerando reprovação da mãe, como ilustra a fala da entrevistada 8:

Ele pede, aí a gente faz o mingau, mas na hora que a gente vai dar ele não queria. Ele ficava dizendo "não quero não, não quero não". O que a gente fazia ele não comia, ficava escolhendo "eu quero isso, eu quero aquilo", a gente dava a ele: "não quero mais não, eu quero aquilo". (Ent.8)

Nesta pesquisa, o medicamento aparece como o único corretor da ausência de alimentação, da falta de apetite. Não há a procura por profissionais de saúde a fim de investigar as causas prováveis da perda de interesse da criança pela alimentação. Também se faz necessário, ao abordar as justificativas para o uso desses medicamentos, investigar os aspectos relacionados aos sentidos atribuídos pelas mães ao tipo de alimento que configura o apetite "normal", apresentado adiante.

\section{O que comer}

$\mathrm{O}$ uso dos medicamentos não se restringia apenas a casos de insatisfação sobre a quantidade de alimento que a criança ingeria, a qual, em alguns casos, podia até 
mesmo agradar às mães. Algumas entrevistadas relataram que seus filhos comiam muito, que seu apetite era normal. Porém, essas mães relatam a frustração quanto ao perfil alimentar da criança, no que tange à escolha dos alimentos. Para as mães, a questão nutricional tornava-se um ponto a ser observado. Havia a concepção do que seriam os alimentos recomendados, os nutricionalmente melhores. Entretanto, esses alimentos não eram habitualmente preferência dos seus filhos.

Para as mães, existem os alimentos que significam "uma refeição” e que devem ser consumidos pelas crianças. De todos, o mais relatado é o feijão, que tem um significado forte, afinal é o alimento mais tradicional do prato do brasileiro. O popular feijão com arroz significa, não somente no campo do básico, mas também do essencial, aquilo que não pode faltar (BARBOSA, 2007).

Ao feijão e ao arroz são atribuídas as propriedades nutricionais elementares, as vitaminas, que por vezes têm que ser repostas.

Porque na verdade merenda não alimenta, não contém como essas outras coisas, feijão, arroz, que tem vitamina, não é mesmo? E merenda não contém isso. Porque o certo mesmo é feijão com arroz. (Ent. 13)

Há questões também de ordem prática. Há alimentos que têm importância maior no sistema classificatório alimentar da mãe e estão alinhados com as condições socioeconômicas em que vive, sendo-lhes atribuído maior valor. Romanelli (2006) acredita que, para a população de baixa renda, há alimentos classificados como comida, como o arroz, feijão e carne. Em suas representações, são alimentos "fortes", que sustentam. Feijāo, arroz e carne são itens certos da refeição dos adultos. Fazem parte, portanto, do cotidiano da família. Fazer com que a criança se alimente da mesma forma que os adultos figura como uma forma de disciplinar o filho. Este agora comerá o que todos os outros na mesa comem. Entrará na normalização.

Se a preferência das crianças não agrada as genitoras, é preciso uma forma de alterar essa seleção. Ao medicamento é atribuída a expectativa de mudar o gosto do filho pelos alimentos. Em sua significação, o aumento da fome, causado pelo medicamento, poderia vencer a resistência da criança em ingerir todos os alimentos sugeridos e desejados pela mãe.

Ele não quer comer feijão. Não quer comer verdura. Ele gosta de comer carne. Ele é abusadinho assim, não é todo suco que ele gosta. Ai ele gosta só de um suco ou dois. (Ent.5) 
O termo "abusadinho" expresso pela mãe sinaliza uma luta de poder entre

mãe e filho. A mãe escolhe o alimento baseado em questões afetivas, nutricionais ou econômicas, caracterizando o seu papel de cuidadora, enquanto o filho rejeita o esforço da mãe, preferindo outros alimentos. Nesse embate, o medicamento é então convocado a exercer um papel disciplinador.

Quando perguntada sobre qual o efeito que ela achava que o medicamento deveria ter, a entrevistada 15 respondeu, evidenciando sua expectativa na mudança do perfil alimentar:

Que mudasse a alimentação dele, o jeito dele comer. Fruta mesmo assim, não toma. Suco toma, mas a fruta mesmo pra ele comer, ele não come. Só banana. Manga, as outras frutas, ele não come. (Ent.15)

Um caso chama a atenção neste estudo: o da entrevistada 12 , que se queixava da alimentação do seu filho quando este estava na casa da avó paterna, onde aparentemente passava bastante tempo, afinal os pais não moravam juntos.

Lá a avó faz as vontades dele, então é só merenda, esses danones, essas coisas, mas é besteira. (Ent.12)

Nesse caso específico, as atitudes da sogra atrapalham a disciplina que a mãe tenta manter. Uma aflição da mãe residia na insistência de seu filho de três anos de manter como refeição principal o mingau:

O dever da gente é ensinar desde bebezinho. Mas o tempo foi passando, foi dando o mingau, ficou o mingau [...]. Nunca teve (falta de apetite). A única coisa é isso, a comida que ele nunca se adaptou, a gente não estimulou ele a comer, só isso [...]. Até hoje ele é assim, ruim de comer. Comida! Assim, refeiçôes normais, feijão, essas coisas que é bom, ele não come. (Ent.12)

A exclamação dessa mãe deixa evidente que ela não classifica o mingau como comida. É apenas um alimento menor. A mãe amamentou o filho até os seis meses, mas, a partir dessa idade, quando é natural e recomendável a inclusão de alimentos sólidos, incluiu o mingau. Porém tarda o filho a trocar de alimento. Sua queixa contra o mingau é tão significativa que durante a entrevista a palavra "mingau" foi empregada exatas 20 vezes. O intuito do uso do medicamento fica claro: despertar o filho para outros alimentos.

Eu fui ao pediatra, dar algum remédio para estimular para ele ter mais fome. Porque na hora que ele tiver com fome mesmo, eu ter a oportunidade de dar o almoço, e não o mingau [...]. Eu imaginei que pelo efeito do remédio ia dar fome, né? Eu aproveitava para dar no lugar do mingau, o almoço, a comida. (Ent. 12) 
Porém, a mãe frustrou-se por não ter conseguido êxito em sua missão. O filho rejeitou a proposta de mudança. Sua rejeição é tanta que chega a quase vomitar quando a mãe tenta administrar outros alimentos.

Uma preocupação exposta pelas mães é quanto à ausência de vitaminas nos alimentos que as crianças preferem. Esses alimentos não teriam as vitaminas necessárias. Para a entrevistada 13 , seria necessária a administração de um polivitamínico para repor as vitaminas não ingeridas:

Porque todas as crianças têm que ter, né? Tem que conter, tem que ter uma vitamina que contém ferro, cálcio, vitamina, né? Ajuda a fortalecer os ossos, né? Acho importante. (Ent.13)

$\mathrm{O}$ uso difundido das vitaminas está muitas vezes conectado à falta de compreensão das necessidades nutricionais por parte dos consumidores, além de práticas mercadológicas que atribuem um valor agregado às vitaminas na busca de uma vida saudável, afinal, a propaganda é utilizada como um instrumento de reforço da já existente cultura da medicalização. Essas experiências conduzem a uma hipervalorização dos produtos farmacêuticos como via de ingestão de vitaminas, associando a uma ideia de se alcançar saúde, bem-estar e, até mesmo, a felicidade (BARROS, 1995; NASCIMENTO; SAYD, 2005).

\section{A busca do corpo infantil desejado}

O antropólogo Le Breton (2003) aponta o corpo do homem contemporâneo como uma estrutura simbólica. Este homem é convidado a construir o corpo, modelando sua aparência, exibindo sua saúde potencial. Trabalhado distintamente ao sujeito, torna-se um objeto à disposição, sobre o qual agir a fim de melhorá-lo.

Nesse sentido, o corpo da criança é o objeto a ser melhorado, pois se desenha como uma forma de apresentação da mãe, da cuidadora, que organiza todas as variáveis que interferem nessa formação. É preciso exibir frente às outras mães a prova do zelo e do cuidado, ressignificando e reafirmando o papel de ser mãe.

Baseando-se na análise da obra de Michel Foucault, Rodrigues (2003, p. 112) nos afirma que "o corpo é sempre uma interpretação. A percepção que possuímos de um corpo depende do olhar que vê este corpo. E este 'olhar' não depende de um sujeito específico, mas de uma 'estrutura', de uma relação de 'olhares'”. Sendo assim, o olhar interpretativo que a mãe lança sobre o corpo do filho depende do olhar que o outro lança sobre esse mesmo corpo. Esse confronto de olhares na 
formação do discurso sobre o corpo constitui relações de poder. Esses discursos, constitutivos de significação, produzem saberes. E esses saberes constituem disciplinas, que visam exercer um controle sobre o corpo e, portanto, exercer poder sobre o corpo (RODRIGUES, 2003).

Não é o caso de contentar-se com o corpo que se tem, mas de modificar suas bases para completá-lo ou torná-lo conforme a ideia que dele se faz. O corpo passa então a ser retocado por motivos de conveniência pessoal (LE BRETON, 2003). Para essa tarefa, pode ser incorporado o emprego de produtos farmacêuticos.

O desejo da mãe está na representação da saúde da criança associada a uma aparência robusta. Portanto, o termo "forte" tem duplo significado: ao mesmo tempo em que quer representar saúde, também significa uma criança com quilos a mais. A entrevistada 13 emprega esse termo ao responder como desejava que a filha fosse:

Mais forte, não gorda né? Porque essa aqui nunca foi gorda. Mas pelo menos tivesse assim um peso mais elevado. Pra você ver, ela come de tudo, é boa de boca, mas engordar que é bom nada. (Ent.13)

A entrevistada 7 também não esconde seu desejo:

A gente quer ver sempre o filho gordinho. (Ent. 7)

É desejo das mães que o peso de seus filhos seja satisfatório, em suas representaçôes do que seja o ideal. Assim, muitas deixaram transparecer que o motivo forte para usar os medicamentos era a constatação que seus filhos apresentavam diminuição do peso.

Ele antes de eu dar a vitamina, ele não aumentava [o peso], ele só fazia diminuir. Sempre abaixo do peso, nunca aumentava. Eu fiquei mesmo preocupada, ele nunca perdeu peso. (Ent.11)

Ao medicamento, é confiada a expectativa de ganho de corpo. O medicamento é o instrumento tecnológico que vai realizar o desejo da mãe, o desejo de modelar o corpo da criança ao que a mãe visualiza como o adequado:

[...] esses remédio [sic] que têm vitamina já é mais pra... eu acho que tanto faz pra acrescentar mais o apetite, como também para desenvolver mais, em termo de corpo. (Ent.13)

Desse modo, o ganho de peso estaria alinhado com a expectativa de crescimento, de desenvolvimento, atendendo ao dito popular "comer pra crescer 
e ficar fortinho". Comer é necessário para promover o crescimento, para poder atingir a saúde.

$\mathrm{O}$ resultado foi que elas ganharam peso. O desenvolvimento foi rápido. Eu achei que desenvolveu bastante. E até hoje, graças a Deus, é a mesma coisa, assim né? Não mudou nada, as meninas cresceram saudáveis. (Ent.10)

À mãe, entrevistada 10, já havia sido vendida a ideia de que o medicamento trazia benefícios para o desenvolvimento de suas crianças, inclusive com aumento da inteligência. Essa ideia acabou por levá-la, mais tarde, a uma farmácia em busca do medicamento:

Pro sono, pra comer, que elas tinham o peso baixo e pra desenvolvimento, porque diziam que desenvolvia rápido e ficava inteligente, essas coisas (risos) [...]. Todo mundo que me ensinava. (Ent.10)

Quando perguntada sobre o objetivo do uso, a entrevistada 10 responde de forma afinada ao que tinha sido recomendado por terceiros:

O objetivo de comer, dormir. Talvez crescer mais rápido [gargalhada]. [Ent. 10]

A resposta, terminada em gargalhadas, parece buscar a cumplicidade do entrevistador ou atenuar o temor de ser caracterizada como tola. Algo de uma proteção antecipada contra o julgamento externo. Sobressai, de qualquer modo, a associação do ganho peso com a aquisição de "inteligência”. O "desenvolvimento" físico, acertadamente, favoreceria o mental. Esse desenvolvimento, porém, acaba reduzindo-se ao ganho de peso, simplesmente, em uma interpretação equivocada do processo de amadurecimento infantil.

Sendo assim, a suplementação com vitaminas também entra como auxiliadora no processo de desenvolvimento, pois seriam elas necessárias ao "fortalecimento" da criança:

Toda criança tem que ter [vitaminas], né, porque esses remédios contêm fósforo, ferro. Então isso ajuda mais no desenvolvimento dela. (Ent.13)

Pelegrin (2008), em sua pesquisa qualitativa com mães, também encontrou projeçōes sobre os filhos dos valores socialmente esperados de ser saudável, forte e inteligente, guardando relação com a boa alimentação. Essa busca pelo peso, que, no íntimo, é a procura da aparência do saudável, pode, conforme exibem alguns estudos, confundir as mães e fazê-las subestimarem um possível excesso de peso dos seus filhos. 


\section{O horário}

Atuando como instrumento disciplinador, o medicamento encontra o destino de buscar ajustar o comer da criança aos horários estabelecidos pelas mães. Comer bem é, para elas, comer no horário. Não se satisfaz a mãe que enxerga no filho a desobediência ao regime alimentar da casa. A residência tem regras próprias e é preciso, portanto, comer na hora que a família estipulou ser a das refeições.

Para a entrevistada 12, era claro que meio dia era o horário de dar o almoço. Esse momento torna-se crucial como o ponto de virada do quadro alimentar do filho. Com esse pensamento, compartilha a ideia de que "meio-dia, todo mundo tem que almoçar". É preciso, então "tirar o mingau dele, dar o almoço". O mingau ficaria deslocado apenas para outros momentos, que não a refeição.

Foi possível reconhecer que a construção que as mães fazem do "comer bem" está envolvida com a questão cronológica, dando ênfase ao horário marcado quando as refeições consagradas pelo hábito e a norma são servidas.

Comer bem é dar o almoço pra ele meio dia e ele se alimentar bem, comer todo. Dar a merenda três horas e ele se alimentar certo. Eu dava e ele não fazia isso, depois que eu dei a vitamina ele começou a almoçar meio dia certo, a merendar três horas certo. (Ent. 11)

Comer bem seria comer nas horas certas, e nas horas certas que é pra gente dar a comida ele não quer de jeito nenhum, fica dando trabalho de comer. (Ent. 8)

Soares e Coelho (2008) assinalaram que o cuidado em oferecer para a criança o alimento em um horário bem definido tem um sentido temporal importante no cotidiano das mães que cuidam, uma vez que é permeado por uma condição de vida que ainda não é reconhecida pela criança.

É possível enxergar na disciplina do horário descrita neste trabalho o que Foucault chamou de produção de "corpos dóceis", uma forma de exercício do poder disciplinar. O corpo, por estar em imerso em um campo político, sofre o efeito da distribuição dos poderes. Passa a ocorrer um movimento de adestramento do corpo, que aqui é visualizado no respeito ao horário. O corpo precisa aprender a comportar-se, ser preciso e ter ritmo. O corpo torna-se útil e eficiente, mas ao mesmo tempo torna-se dócil e submisso. A estratégia do poder disciplinar é docilizar o corpo para torná-lo produtivo (FOUCAULT, 1987).

Quando Foucault fala dessa mecânica do poder, fala de sua forma capilar de existir, no ponto em que o poder encontra o nível dos indivíduos. É um 
poder que está na realidade mais concreta e mais cotidiana, um poder que está tão próximo dos indivíduos que eles não têm como evitá-lo. Esse poder se exerce sobre o próprio "corpo", intervindo direta e materialmente sobre ele, inserindo-se em seus gestos, suas atitudes, seus discursos, sua aprendizagem, sua vida cotidiana. Esse poder significa o controle diário, sistemático, repetitivo e minucioso do comportamento cotidiano do corpo de cada um (FOUCAULT, 1987; RODRIGUES, 2003).

A tecnologia farmacêutica, na figura do medicamento, surge desse modo como instrumento auxiliar e precoce de domínio do outro, tendo na mãe a agente privilegiada, capturada pelo desejo de melhor cuidar em uma condição restritiva da sua capacidade de oferta de alimentos e dos conflitos que a normalização das práticas nutricionais proporciona. A respeito da norma, Urrego (2015) lembra que ela é uma construção processual que se fortalece por meio da interação entre a criança e seus pais, mas que é utópico considerar que as crianças possam aprender regras impostas coercitivamente.

Sendo assim, passar a comer o que o resto da família come deveria ser um processo gradual de abertura do paladar e construção da identidade com autonomia. Entretanto, o medicamento surge como intermediário que abrevia esse processo e compromete as relações da criança com a comida e com a própria família, além de ser, em si, um ato de alienação da vontade e submissão que acontece desde muito cedo (APARICI, 2007).

\section{Conclusões}

Recai tradicionalmente sobre a mãe a responsabilidade de educar e disciplinar o filho em relação à alimentação. Essa tarefa é exercida carregada de crenças, signos e subjetividades. A recusa da criança quanto ao comer e a seletividade alimentar representam um desafio ao poder materno de garantir a alimentação e educar ao comer.

O medicamento é empregado, nessa esfera, como um instrumento disciplinador para que o filho coma na quantidade desejada pela mãe e na forma que se entende como melhor para ele. Sobre o medicamento, ainda é depositada a responsabilidade de promover o ganho de peso da criança, ajudando-a no desenvolvimento físico, além de discipliná-la a se alimentar no horário que a mãe determina. 
O estudo mostrou que as mulheres entrevistadas demarcam suas práticas por

meio de suas representações sociais acerca dos alimentos, do comer infantil e dos medicamentos estimulantes do apetite.

As conclusões deste estudo tornam-se relevantes para o direcionamento das ações de saúde, lembrando que é necessário o reconhecimento, por parte dos profissionais de saúde, das subjetividades e dos aspectos simbólicos que envolvem a alimentação da criança. Esse entendimento propicia maior proximidade com as mães e maior auxílio na condução de escolhas racionais no cuidado materno. ${ }^{1}$

\section{Referências}

APARICI, E.Z. Aprender a comer: procesos de socialización e "Trastornos del Comportamiento Alimentario". 2007. 504 f. Tese (Doutorado em Antropologia Social e Cultural) - Universitat de Barcelona, Barcelona, Espanha, 2007.

AQUINO, D.S. Por que o uso racional de medicamentos deve ser uma prioridade? Ciência \& Saúde Coletiva, Rio de Janeiro, v. 13, p. 733-736, 2008.

BARBOSA, L. Feijão com arroz e arroz com feijão: o Brasil no prato dos brasileiros. Horiz. antropol., Porto Alegre, v. 13, n. 28, 2007.

BARKER, M. et al. Constraints on food choices of women in the UK with lower educational attainment. Public Health Nutr., v. 11, n. 12, p. 1229-37, 2008.

BARROS, J.A.C. A propaganda de medicamentos: atentado à saúde? São Paulo: Hucitec, 1995. BOA-SORTE, N. et al. Percepção materna e autopercepção do estado nutricional de crianças e adolescentes de escolas privadas. J. Pediatr., Rio de janeiro, v. 83, n. 4, p. 349-335, 2007.

CANGUILHEM, G. O normal e o patológico. 6. ed. Rio de Janeiro: Forense Universitária, 2009. CASTRO, C.G.S. O. Estudos de utilização de medicamentos: noçôes básicas. Rio de Janeiro: Editora Fiocruz, 2000.

CERRO, N. et al. Eating behaviour of children 1.5-3.5 years born preterm: parents' perceptions. J. Pediatr. Child Health, v. 38, p. 72-78, 2002.

CHUPROSKI, P.; MELLO, D.F. Percepção materna do estado nutricional de seus filhos. Rev. Nutr. Campinas, v. 22, n.6, nov./dez. 2009.

EXPERTISE COLLECTIVE. Inégalités sociales de santé en lien avec l'alimentation et l'activité physique. Paris: Institut national de la santé et de la recherche médicale, 2014.

FOUCAULT, M. Em defesa da sociedade. São Paulo: Martins Fontes, 2005. . Vigiar epunir: nascimento da prisão. (trad. Raquel Ramalhete) Petrópolis: Vozes, 1987. JAIN, A. et al. Why Don't Low-Income Mothers Worry About Their Preschoolers Being overweight? Pediatrics, v. 107, n. 5, 2001. 
JODELET, D. As representaçôes sociais. Rio de Janeiro: Eduerj, 2001.

KACHANI, A.T. et al. Seletividade alimentar da criança. Pediatria, São Paulo, v. 27, n. 1, p. 48-60, 2005.

LE BRETON, D. Adeus ao corpo. Campinas: Papirus, 2003.

MARTIN, V.B.; CASTILlO, C.D. El niño que no quiere comer. Rev. Chil. Pediatric, Santiago, v. 71, n. 2, 2000.

MINAYO, M. C. S. O desafio do conhecimento: pesquisa qualitativa em saúde. 5. ed. São Paulo: Hucitec, 1998.

MOSCOVICI, S. O fenômeno das representaçôes sociais. In: Representações Sociais: investigações em psicologia social. Petrópolis: Vozes, 2005.

NASCIMENTO, A.C.; SAYD, J.D. "Ao persistirem os sintomas, o médico deverá ser consultado". Isto é regulação? Physis, Rio de Janeiro, v. 15, n. 2, p. 305-328, 2005.

NASCIMENTO, M.C. Medicamentos, comunicação e cultura. Ciênc. Saúde coletiva, Rio de Janeiro, v.10, 2005.

PELEGRIN, R.C.P. O cuidado com a alimentação de crianças menores de um ano na perspectiva materna. 2008. 167 p. Dissertação (Mestrado em Enfermagem em Saúde Pública) - Escola de Enfermagem de Ribeirão Preto, Universidade de São Paulo, 2008.

POCKELS, R. et al. Uso de estimulantes del apetito en la población infantil. Arch. domin. Pediatr., v. 30, n. 2, p. 30-32, 1994.

RAMOS, M.; STEIN, L.M. Desenvolvimento do comportamento alimentar infantil. $J$. Pediatr., v. 76, supl 3, p. 229-237, 2002.

RODRIGUES, S.M. A relação entre o corpo e o poder em Michel Foucault. Psicologia em Revista, Belo Horizonte, v. 9, n. 13, p. 109-124, 2003.

ROMANELLI, G. O significado da alimentação na família: uma visão antropológica. Medicina, Ribeirão Preto, v. 39, n. 3, p. 333-339, 2006.

SALVE, J.M.; SILVA, I.A. Representações sociais de mães sobre a introdução de alimentos complementares para lactentes. Acta Paul Enferm., v. 22, n. 1, p. 43-48, 2009.

SIMON, V.G.N.; SOUZA, J.M.P.; SOUZA, S.B. Introdução de alimentos complementares e sua relação com variáveis demográficas e socioeconômicas, em crianças no primeiro ano de vida, nascidas no Hospital Universitário no município de São Paulo. Rev. Bras. Epidemiol., v. 6, n. 1, p. 29-38, abr. 2003.

SOARES, M.D. Práticas de cuidado alimentar de crianças e sentidos atribuidos aos discursos sobre alimentação e nutrição por cuidados alimentares. 2011, 158 f. Tese (Doutorado em Saúde Coletiva) - Programa de Pós graduação em Saúde coletiva, Universidade Federal da Bahia, 2011. 
SOARES, M.D; COELHO, T.C.B. O cotidiano do cuidado infantil em comunidades rurais do Estado da Bahia: uma abordagem qualitativa. Rev. Bras. Saude Matern. Infant., Recife, v. 8, n. 4, 2008.

STEFANELLO, J. Representação social de mulheres/mães sobre as práticas alimentares de crianças menores de um ano. 2008. 198 f. Tese (Doutorado em Enfermagem em Saúde Pública) - Programa de Pós-Graduação em Enfermagem em Saúde Pública, Universidade de São Paulo, Ribeirão Preto, 2008.

URREGO, L.M.G. El espacio y su uso en la construcción social de la norma. Zona Prox. Barranquilla, n. 23, p. $49-72,2015$.

\section{Nota}

${ }^{1}$ D.C. Ramos participou da concepção, planejamento, análise e interpretação dos dados, além da elaboração do manuscrito. T.C.B. Coelho participou da análise e interpretação dos dados, realizou a revisão crítica do conteúdo e colaborou na redação da versão final do artigo. 
Social representation of mothers about feeding and use of appetite stimulants in children: satisfaction, normality and power This study aimed to identify the social representations elaborated by mothers about the appetite of children and the drugs used to modify this appetite. The qualitative approach used in this study employed as theoretical support the theory of social representations. Through interviews with 15 mothers who administered their children drugs to stimulate appetite, it was possible to identify a maternal dissatisfaction with the usual volume and selectivity of food eaten by their children. These were the main reasons for using drugs. Other related reasons were the growth of the children, with a body mass gain, beyond the desire to regulate the times which the child should eat. These results point to the importance of maternal social representations of body perception, and the role of food and medicine in child care practices.

> Keywords: children's nutrition; social representations; appetite stimulant. 